\title{
Peripheral nerve function in chronic liver disease
}

\author{
K. N. SENEVIRATNE AND O. A. PEIRIS \\ From the Departments of Physiology and Medicine, University of Ceylon, Colombo
}

SUMMARY Peripheral nerve function has been studied in 50 patients with chronic liver disease. An increase in the latency or a reduction in the response amplitude of the evoked sensory potential of the median nerve was detected in 34 of the 50 subjects. This was in striking contrast to the paucity of neurological signs and symptoms suggestive of peripheral nerve damage seen in these patients. There was no evidence to show that alcohol was responsible for the neuropathy. Abnormalities in the excitability changes of sensory nerve during ischaemia were detected in seven of the 16 subjects whose distal sensory latencies were within normal limits. A critical evaluation of the hypotheses which have been postulated to account for the increased resistance of peripheral nerve to inactivation by ischaemia has been made. It is concluded that an increase of the permeability of the periaxonal diffusion barrier to $\mathrm{K}$ offers the most acceptable explanation for this phenomenon.

Dayan and Williams (1967) have reported the occurrence of segmental demyelination in peripheral nerves of 10 patients with chronic liver disease. They suggest that the Schwann cell damage which causes selective demyelination could be due to the accumulation of unidentified toxic metabolites resulting from liver cell damage. Alternatively, they suggest that the association of diabetes mellitus with chronic liver disease could account for the nerve damage which could then be considered a diabetic neuropathy. Denny-Brown (1958) demonstrated the presence of segmental demyelination in the most distal parts of peripheral nerves in subjects with alcoholic neuropathy. Similar changes have also been seen in human beriberi and in rats with chronic thiamine deficiency (North and Sinclair, 1956). Simpson (1962) has drawn attention to the fact that elevations of blood pyruvate levels have been reported in several different toxic and metabolic neuropathies, and related this to the critical role which the B group vitamins thiamine, nicotinamide and pantothenic acid played in the decarboxylation of pyruvic acid during the oxidative metabolism of glucose, a process on which normal nerve tissue is completely dependant for its energy requirements. Mawdsley and Mayer (1965) found evidence of liver damage in several of their subjects with alcoholic neuropathy, and have suggested that a deficiency of lipoic acid synthesis may play a part in the development of the neuropathy, since lipoic acid too is known to be an essential coenzyme associated with thiamine in the initial decarboxylation of keto acids.

The functional changes seen in peripheral nerves with segmental demyelination are of considerable interest. The association of demyelination with a reduction of conduction velocity in a variety of human and experimental neuropathies is now well established (Gilliatt, 1966). More recently several studies have drawn attention to conditions in which the demyelination is associated with an increased resistance of nerve to inactivation by ischaemia. This phenomenon has since been demonstrated in diabetes (Steiness, 1959; Castaigne, Cathala, Dry, and Mastropaolo, 1966; Gregersen, 1968; Seneviratne and Peiris, 1968b), in motor neurone disease (Shahani and Russell, 1969), and in uraemia (Christensen and Ørskov, 1969).

This study was undertaken to assess the extent to which a peripheral neuropathy occurred in chronic liver disease and to ascertain the possible roles of alcohol and diabetes in the genesis of the neuropathy. The experiments were also designed to test the validity of Christensen and Ørskov's (1969) contention that the increased resistance of the nerve 
to ischaemia was determined primarily by the shortening of the saltatory conduction distances as a result of the demyelination.

\section{METHODS}

Glucose tolerance tests were done using a $50 \mathrm{~g}$ oral dose of glucose in patients suffering from chronic liver disease. Fifty patients between the ages of 20 to 50 years who had normal glucose tolerances as judged by the criteria laid down by the World Health Organization (1965) were selected for this study. Clinically detectable hepatomegaly was present in all subjects and the details of the biochemical abnormalities are shown in Table 1. Bromsulphthalein (BSP) excretion was done in eight of these cases, since the other liver function tests gave doubtful results of dysfunction. Hepatic biopsies were done on three patients in this series. All of these had evidence of well-compensated portal cirrhosis, though they had no detectable biochemical changes suggestive of hepatic failure.

TABLE 1

LIVER FUNCTION TESTS ON 50 SUBJECTS

\begin{tabular}{cccccc}
\hline $\begin{array}{c}\text { Serum } \\
\text { bilirubin } \\
>1.0 \mathrm{mg} / \\
100 \mathrm{ml} .\end{array}$ & $\begin{array}{c}\text { Serum } \\
\text { albumin } \\
<3 \mathrm{~g} / 100 \\
\mathrm{ml} .\end{array}$ & $\begin{array}{c}\mathrm{ZnSO}_{4} \\
\text { focculation } \\
>12 u .\end{array}$ & $\begin{array}{c}\text { Thymol } \\
\text { turbidity } \\
>5 \mathrm{u} .\end{array}$ & $\begin{array}{c}\text { One-stage } \\
\text { pro-thrombin } \\
\text { time } \\
>17 \mathrm{sec}\end{array}$ & $\begin{array}{c}\text { BSP } \\
\text { in } \begin{array}{c}45 \mathrm{~min} \\
>3 \%\end{array}\end{array}$ \\
\hline 36 & 27 & 42 & 23 & 30 & 8 \\
\hline
\end{tabular}

The aetiology of the liver damage in these cases is shown in Table 2. Alcohol was assumed to have played a part in causing hepatic damage in cases where there was an average consumption of at least two bottles of spirits or an equivalent quantity of milder alcoholic drink per week for a period of two years or more immediately preceding the present illness. All patients included in the post-viral hepatitis group had their acute episode at least six months before this study.

TABLE 2

AETIOLOGY OF LIVER DISEASE

\begin{tabular}{lccc}
\hline & Alcoholic & Post-viral & Cryptogenic \\
\hline Males & 22 & 2 & 9 \\
Females & 0 & 5 & 12 \\
\hline
\end{tabular}

A detailed clinical assessment of the evidence of peripheral nerve damage was made in all cases by one of us. Distal motor latency in one median nerve was recorded using a concentric needle electrode inserted into the abductor pollicis brevis muscle. The sensory nerve potential evoked in the distal segment of the median nerve by a supramaximal stimulus was recorded by the method described previously (Seneviratne and Peiris, 1968a). These distal motor and sensory latencies were compared with results obtained from $\mathbf{5 0}$ healthy subjects of a comparable age group. The response of the evoked sensory nerve potential to ischaemia produced by an inflated pneumatic cuff applied to the upper limb for 30 minutes was studied in 16 patients who had sensory nerve potentials of normal amplitude and latency. The details of the technique used have been described previously (Seneviratne and Peiris, 1968a).

\section{RESULTS}

Figure 1 illustrates the distribution of distal motor latencies in the median nerve in the patients with chronic liver disease in comparison with those of the controls. In the controls the mean latency was $3.1 \mathrm{msec}$ (range 2.0 to $4.5 \mathrm{msec}, \mathrm{SD} \pm 0.6 \mathrm{msec}$ ); in the group with liver disease it was $4.0 \mathrm{msec}$ (range 2.6 to $6.4 \mathrm{msec}, \mathrm{SD} \pm 0.7 \mathrm{msec}$ ). Ten of these subjects had latencies increased beyond the upper limit of the normal group, of these four were from the alcoholic group and six from among the non-alcoholic group.

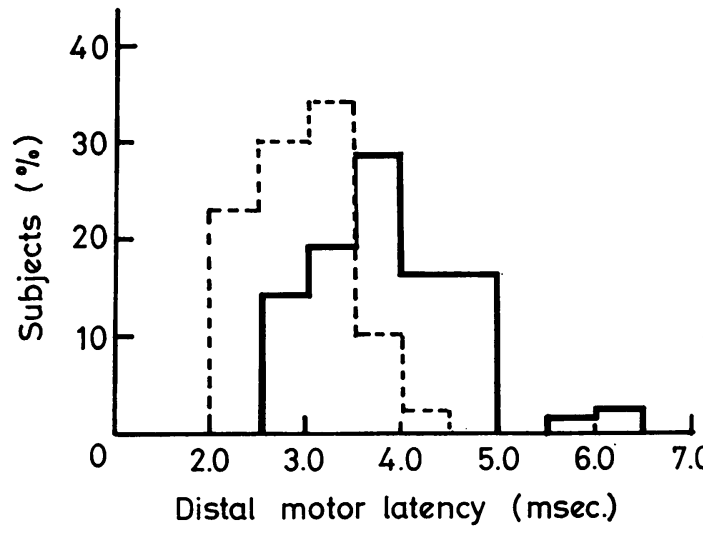

FIG. 1. Distribution of distal motor latencies in 50 healthy controls (interrupted line) and in 50 patients (continuous line) with chronic liver disease.

Figure 2 illustrates the distribution of the amplitudes and latencies of the compound sensory nerve action potential evoked by supramaximal stimulation of the digital branches of the median nerve. In the control group the mean amplitude of the response was $102 \mu \mathrm{V}$ (range 66 to $140 \mu \mathrm{V}, \mathrm{SD} \pm$ $24.2 \mu \mathrm{V}$ ), while the mean latency was $2.0 \mathrm{msec}$ (range 1.7 to $2.7 \mathrm{msec}, \mathrm{SD} \pm 0.2 \mathrm{msec}$ ).

Table 3 summarizes the results obtained from the patients with liver disease. Sixteen of the 50 subjects studied had sensory nerve potentials of normal latency and amplitude, while 34 had responses of reduced amplitude. Of these 34 subjects 15 were 


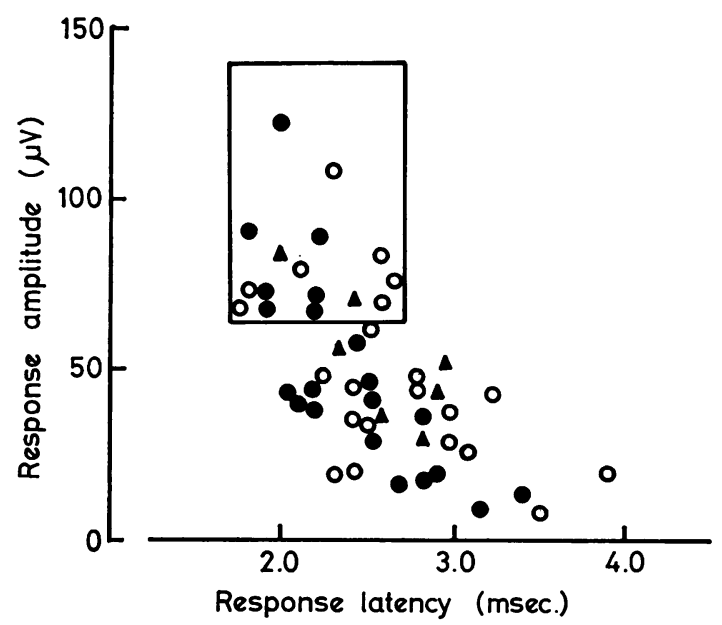

FIG. 2. Distribution of response amplitudes and latencies of the evoked compound sensory nerve action potential in 50 patients with chronic liver disease. $O=$ alcoholic; = cryptogenic; $\Delta=$ post-viral hepatitis. The rectangle defines the limits of values obtained from 50 healthy controls.

\section{TABLE 3}

EVOKED SENSORY NERVE POTENTIALS IN 50 PATIENTS WITH CHRONIC LIVER DISEASE

\begin{tabular}{lcccc}
\hline & Alcohol & Post-viral & Cryptogenic & Total \\
\hline $\begin{array}{l}\text { Normal latency } \\
\text { Normal amplitude }\end{array}$ & 7 & 2 & 7 & 16 \\
$\begin{array}{l}\text { Normal latency } \\
\text { Reduced amplitude }\end{array}$ & 7 & 2 & 9 & 18 \\
$\begin{array}{l}\text { Reduced latency } \\
\text { Reduced amplitude }\end{array}$ & 8 & 3 & 5 & 16 \\
\hline
\end{tabular}

from the alcoholic group and 19 from the nonalcoholic group. There was no significant difference between the distribution of latencies or response amplitudes between these two groups. Excitability changes in the sensory nerve during a 30 minute period of limb ischaemia were studied in the 16 subjects who had sensory nerve potentials of normal amplitude and latency. In nine the excitability changes were similar to those seen in the healthy controls. In these, the response to a sub-maximal stimulus of constant size was abolished within 30 minutes of ischaemia. With release of the vascular occlusion the response grew very rapidly in size, resting amplitudes being regained in three to five minutes. As with the healthy controls, all these subjects experienced ischaemic and post-ischaemic paraesthesiae during the early phases of the ischaemic and post-ischaemic periods. Seven subjects with liver disease who had action potentials of normal amplitude and latency showed an abnormal resistance of their peripheral nerves to inactivation by ischaemia. At the end of a 30 minute period of vascular occlusion the amplitude of the sensory nerve potential remained at 32 to $80 \%$ (mean $54 \%$ ) of the resting size. Release of the cuff was followed by a much slower restitution of the potential size, resting amplitudes being reached in not less than 15 minutes after restoration of the blood supply. The absence of post-ischaemic paraesthesiae was a characteristic feature in all these subjects. Figure 3 illustrates the changes in response amplitude seen in one of these subjects. Of the seven subjects showing an abnormal response to ischaemia two were alcoholics, while five were from the non-alcoholic group.

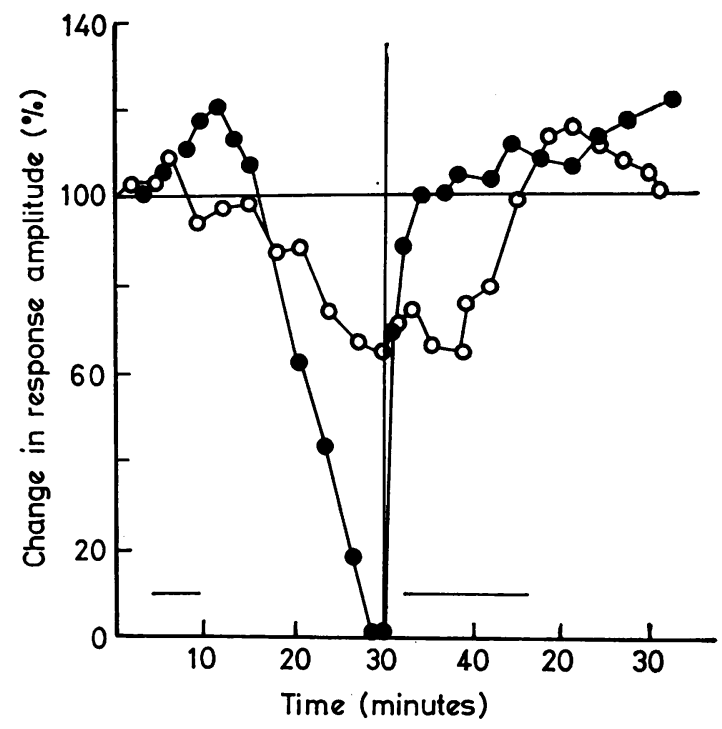

FIG. 3. Percentage change of response amplitude evoked by a sub-maximal stimulus of constant strength, during and after a 30 minute period of ischaemia. $=$ control subject; $\bigcirc=$ patients with chronic liver disease. Horizontal lines parallel to the abscissa indicate times of onset and duration of paraesthesiae in the control subject.

Of the 34 subjects who had electro-diagnostic evidence of a peripheral nerve conduction defect only four had clinically detectable evidence of a peripheral neuropathy.

\section{DISCUSSION}

The results obtained show that 34 of the 50 patients studied had evidence of a peripheral sensory nerve 
conduction defect, while 10 of the 50 had increased distal motor latencies. These results support the observations of Dayan and Williams (1967) who demonstrated histological evidence of demyelination in the sural nerve fibres of all their subjects. Our results also confirm earlier observations that evoked sensory nerve potentials are a more sensitive index of a mixed peripheral nerve lesion than are the corresponding distal motor latencies, and draw attention to the striking disparity between the electro-diagnostic evidence of nerve damage seen in these 34 subjects and the clinically detectable evidence of a neuropathy which was seen in only four of this group.

The absence of any significant differences in any of the parameters of nerve function between the subjects in the alcoholic and non-alcoholic groups serves to exclude alcohol as the causative factor of the nerve damage in subjects with chronic liver disease and is in accordance with the views of Dayan and Williams (1967) who concluded that alcohol was not likely to be the cause of the demyelination seen in their patients. The occurrence of a derangement of glucose metabolism of the diabetic type in patients with chronic liver disease suggests that the nerve damage seen in these patients may be a 'diabetic' neuropathy. This factor was investigated by excluding from our series all those patients who had abnormal glucose tolerance curves. Evidence of nerve damage seen in our series would therefore exclude this abnormality of glucose metabolism as the causative factor of nerve damage.

Seven of our subjects who had no other evidence of nerve dysfunction showed an abnormal resistance of their peripheral sensory nerves to inactivation by ischaemia. These seven subjects did not experience the ischaemic and post-ischaemic paraesthesiae which occur with great constancy in healthy subjects during and after a short period of vascular occlusion in a limb (Poole, 1956a). Poole (1956b) has also shown that paraesthesiae were either absent or grossly reduced in intensity or duration in healthy subjects of over 60 years of age, in subjects with a variety of peripheral nerve disorders and in subjects with motor neurone disease. Seneviratne and Peiris (1968a and b) have shown that in healthy subjects the periods during which paraesthesiae are felt correlate well with the transient phases of nerve hyperexcitability which occur during the early ischaemic and post-ischaemic periods.

The results obtained from seven subjects in this series and from diabetic subjects (Seneviratne and Peiris, 1968b) differ markedly from that of the controls in that the nerves of these subjects are incompletely inactivated by a 30 minute period of limb ischaemia, and in that they show reduced rates of increase of excitability during the early ischaemic and post-ischaemic periods. These same features have since been demonstrated in the isolated peripheral nerves of alloxan-diabetic rats during exposure to hypoxic and anoxic gas mixtures (Seneviratne and Peiris, 1969, 1970). An increased resistance to ischaemic inactivation has also been demonstrated in the peripheral nerves of subjects with motor neurone disease (Shahani and Russell, 1969) and in uraemia (Christensen and Ørskov, 1969). There is, however, no consensus of opinion regarding the pathophysiological processes responsible for this phenomenon. Three hypotheses have been postulated to account for these changes. Steiness (1963), Gregersen (1968), and Shahani and Russell (1969) have suggested that a metabolic abnormality of the nerve may enable it to maintain energy synthesis even under ischaemic conditions, permitting these nerves to maintain membrane polarization for longer periods than control nerves. There is, however, no direct evidence for such a metabolic pathway which could account for the continued energy synthesis in conditions as disparate as diabetes, uraemia, chronic liver disease, motor neurone disease, alloxan-diabetes, and old age.

Christensen and Ørskov (1969) have suggested 욱 that the resistance of the nerve to ischaemia is due to the formation of new points of depolarization between the nodes of Ranvier. It is argued that such a reduction of the saltatory conduction distance would allow nerve conduction to continue at lower membrane potential. It is suggested that the persistence of sensory perception in an ischaemic limb occurs because of the formation of new intermediate points of depolarization in every internode along the length of nerve distal to the point of vascular occlusion. Several difficulties arise in accounting for the experimental evidence available on the basis of this hypothesis. A consideration of the cable properties of nerve predicts that a shortening of the saltatory conduction length must be accompanied by a significant diminution of nerve conduction velocity, for a shorter saltatory distance would imply a shorter space constant, and consequently a reduced conduction velocity even if the membrane resistance remained constant. A reduction of the internode membrane resistance, as has been demonstrated by Eliasson (1969) in the nerves of alloxan-diabetic rats, would contribute to an even greater reduction of the conduction velocity. The experimental results obtained in this study and from diabetic subjects (Seneviratne and Peiris, 1968b) do not support this contention, for they have shown that even subjects with normal motor and sensory nerve conduction velocities exhibit the property of 
increased resistance of peripheral nerve to ischaemia. Further, if a new site of depolarization, capable of maintaining saltatory conduction by a flow of local circuit current, were to arise in the internode, it is necessary that there should be a significant increase of membrane capacitance at that point. Tasaki (1955) demonstrated such a change in the frog nerve, when a new point of depolarization was produced in the internode by the application of saponin. Eliasson (1969) found no significant change in the internodal membrane capacitance of alloxanized rat nerve, although such nerves have been shown to be abnormally resistant to the effects of hypoxia (Seneviratne and Peiris, 1969, 1970). Christensen and Ørskov's hypothesis also requires that internodal demyelination must occur at every internode along a fibre before the increased resistance to ischaemia develops and implies that this condition occurs even in newly diagnosed diabetes. The histological evidence does not support this view. The results of Thomas and Lascelles (1966) clearly show the presence of shortened and demyelinated internodes intercalated between internodes of normal length and myelin configuration along the course of a single fibre. Similar changes have been demonstrated in the nerves of alloxan diabetic rats by Lovelace (1967), Hildebrand, Joffroy, Graff, and Coërs (1968), and Seneviratne and Peiris (1969). These studies show that fibres of normal internodal length and appearance can be demonstrated even in the nerves of severely diabetic animals, and that the earliest discernible change consists of a paranodal rather than an internodal demyelination.

The third hypothesis postulates the existence of a relatively impermeable periaxonal diffusion barrier in normal nerve which serves to limit the rate of ion exchange between axon and extracellular fluid (Seneviratne and Peiris, 1970). Under ischaemic conditions, inactivation of the membrane energy synthesis mechanisms would lead to an efflux of $\mathrm{K} \cdot$ from the axon. This periaxonal accumulation of $\mathrm{K} \cdot$ would result in the progressive lowering of membrane potential. This would lead, first, to an increased excitability of the nerve, as the critical membrane threshold value was reached, later it would lead to a conduction block as the continued depolarization reduces and inactivates membrane sodium ion conductance. It is suggested that the permeability of this periaxonal diffusion barrier increases as a non-specific response to a variety of toxic and metabolic insults. Such a change would retard the rate of periaxonal $\mathrm{K}^{\cdot}$ accumulation and delay the onset of conduction block. This hypothesis is in good accord with all the experimental evidence available to date. Thus, it could account for the absence of paraesthesiae in these subjects, for paraesthesiae have been shown (Seneviratne and Peiris, 1968a) to occur only when the rate of increase of nerve excitability is rapid. Since new node formation is not an essential prerequisite for diffusion barrier permeability changes, the property of increased resistance to ischaemia would be independent of conduction velocity changes. This hypothesis is also strongly supported by Eliasson's (1969) findings of a reduced internode membrane resistance coupled with an unaltered membrane capacitance. The normalization of the ischaemic threshold of early diabetics during active insulin therapy (Gregersen, 1968) is likely to be due to the increased concentration of intracellular $\mathrm{K} \cdot$ under the influence of insulin. In the early diabetic, where periaxonal membrane damage is not likely to be extensive, the increased initial intracellular $\mathbf{K}^{\cdot}$ concentration would cause an increased $\mathrm{K}^{\cdot}$ efflux during ischaemia. This increased efflux could raise the periaxonal $K^{\cdot}$ concentration to inactivation levels if the diffusion barrier permeability is not excessive. In the chronic diabetic, however, even active insulin therapy would not cause a normalization of the ischaemic threshold, as the extensively damaged periaxonal barrier would be ineffective in maintaining the high level of periaxonal $\mathrm{K} \cdot$ concentration required to produce a conduction block. The results of experiments with insulin on the rate of inactivation of normal and diabetic rat nerve during exposure to hypoxia (Seneviratne and Peiris, 1970) adduce strong evidence in favour of the argument outlined above.

We are grateful to the physicians of the General Hospital, Colombo, for giving us access to patients under their care. One of us (K. N. Seneviratne) is in receipt of research grants from the University of Ceylon, Colombo, and the Ministry for Scientific Research of the Government of Ceylon.

\section{REFERENCES}

Castaigne, P., Cathala, H. P., Dry, J., and Mastropaolo, C. (1966). Les responses des nerfs et des muscles à des stimulations electriques au cours d'une épreuve de garrot ischemique chez l'homme normal et chez le diabetique. Rev. neurol., 115, 61-66.

Christensen, N. J., and Ørskov, H. (1969). Vibratory perception during ischaemia in uraemic patients with mild carbohydrate intolerance. J. Neurol. Neurosurg. Psychiat., 32, 519-524.

Dayan, A. D., and Williams, R. (1967). Demyelinating peripheral neuropathy and liver disease. Lancet, $2,133-$ 134.

Denny-Brown, D. (1958). The neurological aspects of thiamine deficiency. Fed. Proc., 17, Suppl. No. 2, 35-39.

Eliasson, S. G. (1969). Properties of isolated nerve fibres from alloxanized rats. J. Neurol. Neurosurg. Psychiat., 32, 525-529. 
Gilliatt, R. W. (1966). Nerve conduction in human and experimental neuropathies. Proc. roy. Soc. Med., 59, 989-992.

Gregersen, G. (1968). A study of the peripheral nerves in diabetic subjects during ischaemia. J. Neurol. Neurosurg. Psychiat., 31, 175-181.

Hildebrand, J., Joffroy, A., Graff, G., and Coêrs, C. (1968). Neuromuscular changes with alloxan-hyperglycemia. Arch. Neurol. (Chic.), 18, 633-641.

Lovelace, R. E. (1967). Experimental neuropathy in rats. made diabetic with alloxan, p. 27. In Proceedings of the International Meeting on Electromyography, Glasgow.

Mawdsley, C., and Mayer, R. F. (1965). Nerve conduction in alcoholic polyneuropathy. Brain, 88, 335-356.

North, J. D. K., and Sinclair, H. M. (1956). Nutritional neuropathy. Chronic thiamine deficiency in the rat. Arch. Path., 62, 341-353.

Poole, E. W. (1956a). Ischaemic and post-ischaemic paraesthesiae: normal responses in the upper limb with special reference to the effects of age. J. Neurol. Neurosurg. Psychiat., 19, 148-154.

Poole, E. W. (1956b). Ischaemic and post-ischaemic paraesthesiae in polyneuritis. J. Neurol. Neurosurg. Psychiat., 19, 281-288.

Seneviratne, K. N., and Peiris, O. A. (1968a). The effect of ischaemia on the excitability of human sensory nerve. J. Neurol. Neurosurg. Psychiat., 31, 338-347.

Seneviratne, K. N., and Peiris, O. A. (1968b). The effect of ischaemia on the excitability of sensory nerves in diabetes mellitus. J. Neurol. Neurosurg. Psvchiat., 31, 348-353.

Seneviratne, K. N., and Peiris, O. A. (1969). The effects of hypoxia on the excitability of the isolated peripheral nerves of alloxan-diabetic rats. J. Neurol. Neurosurg. Psychiat., 32, 462-469.

Seneviratne, K. N., and Peiris, O. A. (1970). The role of diffusion barriers in determining the excitability of peripheral nerve. J. Neurol. Neurosurg. Psychiat., 33, In press.

Shahani, B., and Russell, W. R. (1969). Motor neurone disease. An abnormality of nerve metabolism. $J$. Neurol. Neurosurg. Psychiat., 32, 1-5.

Simpson, J. A. (1962). The neuropathies. In Modern Trends in Neurology, Series 3, pp. 245-291. Edited by D. J. Williams. Butterworth: London.

Steiness, I. B. (1959). Vibratory perception in diabetics during arrested blood flow to the limb. Acta med. scand., 163, 195-205.

Tasaki, I. (1955). New measurements of the capacity and the resistance of the myelin sheath and the nodal membrane of the isolated frog nerve fiber. Amer. J. Physiol., 181, 639-650.

Thomas, P. K., and Lascelles, R. G. (1966). The pathology of diabetic neuropathy. Quart. J. Med., 35, 489-509.

World Health Organization (1965). Diabetes mellitus. Report of a W.H.O. expert committee. Wld Hlth Org. techn. Rep. Ser., 310, 44. 